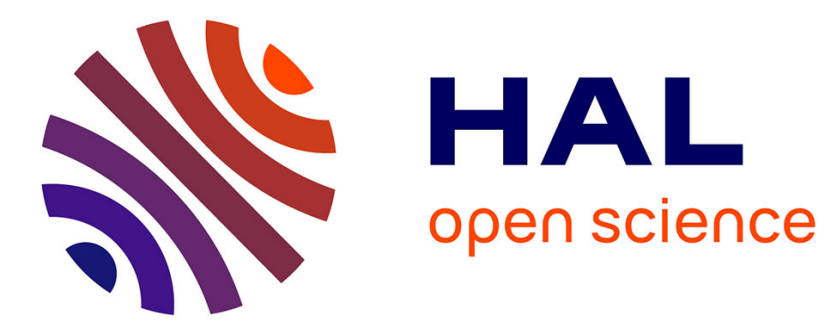

\title{
THE INFLUENCE OF WATER VAPOR ON THE SELECTIVE LOW PRESSURE CVD OF COPPER
}

B. Lecohier, J.-M. Philippoz, B. Calpini, T. Stumm, H. van den Bergh

\section{To cite this version:}

B. Lecohier, J.-M. Philippoz, B. Calpini, T. Stumm, H. van den Bergh. THE INFLUENCE OF WATER VAPOR ON THE SELECTIVE LOW PRESSURE CVD OF COPPER. Journal de Physique IV Proceedings, 1991, 02 (C2), pp.C2-279-C2-286. 10.1051/jp4:1991234 · jpa-00249823

\section{HAL Id: jpa-00249823 https://hal.science/jpa-00249823}

Submitted on 1 Jan 1991

HAL is a multi-disciplinary open access archive for the deposit and dissemination of scientific research documents, whether they are published or not. The documents may come from teaching and research institutions in France or abroad, or from public or private research centers.
L'archive ouverte pluridisciplinaire HAL, est destinée au dépôt et à la diffusion de documents scientifiques de niveau recherche, publiés ou non, émanant des établissements d'enseignement et de recherche français ou étrangers, des laboratoires publics ou privés. 
Colloque C2, suppl, au Journal de Physique II, Vol. 1, septembre 1991

THE INFLUENCE OF WATER VAPOR ON THE SELECTIVE LOW PRESSURE CVD OF COPPER

B. LECOHIER, J.-M. PHILIPPOZ, B. CALPINI, T. STUMM and

H. VAN DEN BERGH

Laboratolre de Chimie Technique, École Polytechnique Fédérale de Lausanne, CH-1015 Lausanne, Switzerland

ABSTRACT Low pressure CVD of copper from its bis-hexafluoroacetylacetonate is studied on oxidized silicon substrates locally seeded with a $2.5 \AA$ platinum prenucleation film. Copper is deposited selectively on top of the prenucleation layer from the gaseous metalorganic compound diluted in hydrogen. The selectivity, growth rate and resistivity of the copper deposit strongly depend on the presence of water vapor in the reagent gas mixture.

\section{INTRODUCTION}

The development of sub-micron metallization techniques is one of the focal points in micro- and opto-electronics. In-situ non-lithographic methods using laser, electron or ion beams may have the potential to revolutionize areas of these technologies. Although the absolute limits of direct writing from the gas, liquid and solid phase have not yet been reached, it appears that an inherent factor which hampers processing with a resolution better than $0.5 \mu \mathrm{m}$ at high speeds is the fact that relatively large amounts of precursor must be transformed into pure metal in a single step. Hence several two-step metallization processes are currently being studied [1-14].

In the first in-situ processing step, the substrate is patterned, for instance with a thin layer of metal (typically of the order of 0.1-10 $\AA$ thickness); this so-called prenucleation process can reach high speeds because only a small amount of precursor material needs to be transformed. In the second step, thick electrically conducting metal deposits are built-up on top of the previously patterned lines; two important requirements for this process are the selectivity (growth on the prenucleated areas and not on the rest of the substrate), and the resolution (the resolution of the patterning step should be maintained).

Different techniques can be used for each of these two steps. The patterning is possible by direct writing (with laser [1-3], electron [4, 15-18] or ion beams [19-22]) or by projection through a mask (with UV light [3] or X-rays). Electroless deposition from a solution [1, 5-7], decomposition from a solid layer [8], and low pressure CVD [3, 9-13] 
have been used for selective metal growth. Another possible application for the low pressure CVD of copper is the selective filling of via holes [23].

In our laboratory we chose as a model system to investigate the effect of different seeding material, particle size and particle number density, on the second (build-up) step. In particular we have concentrated on the deposition of copper from a gas phase precursor on $\mathrm{SiO}_{2}$ surfaces partially covered with metal prenucleation layers. In previous work [23], we showed that selective copper deposits can be obtained on ultrathin prenucleation layers of several metals ( $\mathrm{Pt}, \mathrm{Pd}, \mathrm{Cu}, \mathrm{Ag}, \mathrm{Au}$, and $\mathrm{W}$ ), and that the morphology, growth rate and resistivity of the copper deposit depend on the prenucleation layer thickness (from submonolayer coverage to several $\AA$ thick). We report here on another observation in the CVD of copper from its bis-hexafluoroacetylacetonate $\mathrm{Cu}(\mathrm{hfa})_{2}$, namely the influence of the addition of water vapor to the gas flow.

\section{EXPERIMENTAL}

Silicon wafers with a $800 \AA$ thick thermally grown oxide layer were used as substrates for these experiments. For good reproducibility, the platinum prenucleation layers were produced by vacuum evaporation using the pendant drop method [24]. This technique gives a well-controlled evaporation rate, which was calibrated in our conditions by measuring relatively thick evaporated layers with a stylus profilometer; this calibration then allowed us to determine the evaporated layer thickness from the evaporation time and the distance between the substrate and the molten platinum drop. During the evaporation, a fine wire mesh grid was placed on the substrate in order to define areas with and without the platinum prenucleation layer.

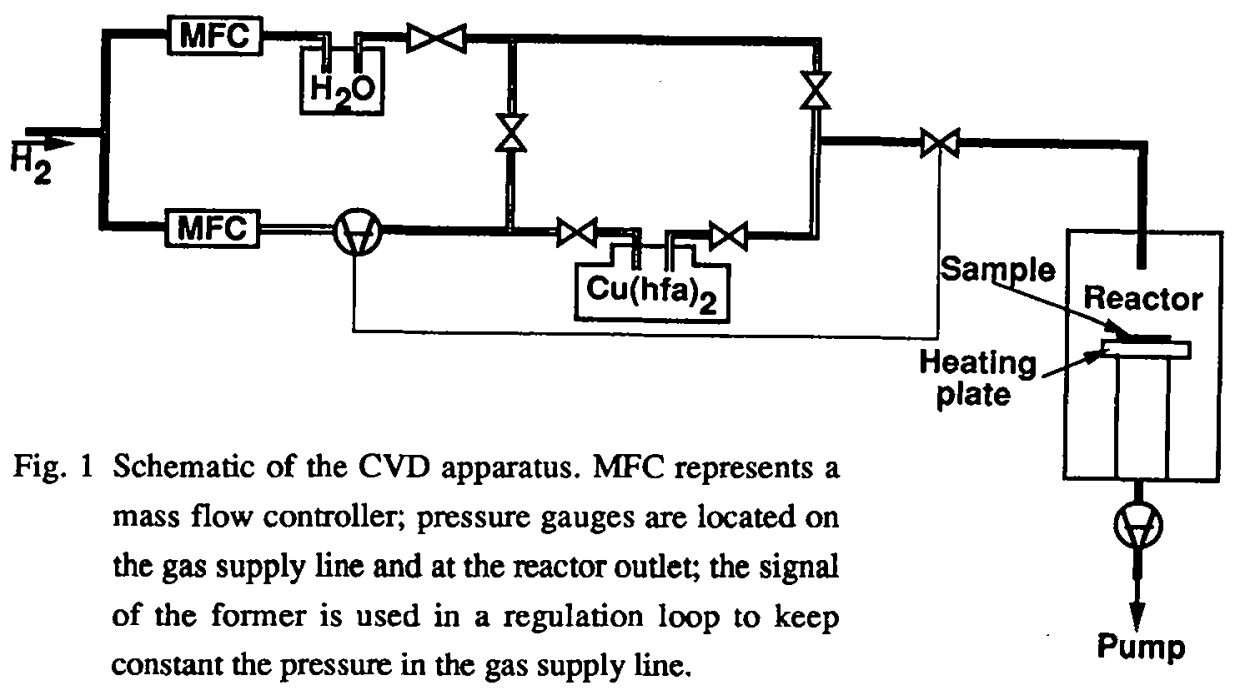


Low pressure CVD was performed in an apparatus consisting of three main parts: the gas supply including two mass flow controllers, the temperature-stabilized containers for $\mathrm{Cu}(\mathrm{hfa})_{2}$ and $\mathrm{H}_{2} \mathrm{O}$, and the cold-wall reactor chamber (see Fig. 1). The green $\mathrm{Cu}(\mathrm{hfa})_{2} \cdot \mathrm{H}_{2} \mathrm{O}$ was purified twice by sublimation, dehydrated to the blue-purple $\mathrm{Cu}(\mathrm{hfa})_{2}$ on $\mathrm{P}_{2} \mathrm{O}_{5}$ and loaded in the container under an inert atmosphere. Doubly distilled water was introduced in the other container. At the beginning of the CVD experiment the system was evacuated to $5 \cdot 10^{-3}$ mbar. A constant hydrogen flow, 50 standard cubic centimeters per minute (sccm), was then supplied during the whole experiment. While the sample was heated up to $400{ }^{\circ} \mathrm{C}$ (measured by a thermocouple located in the aluminum block used as sample holder), the total hydrogen flow was sent directly through the reactor, by-passing both the precursor and water containers. At the same time, these containers were thermostatted at the temperature corresponding to the desired equilibrium vapor pressure: $60^{\circ} \mathrm{C}$ for $\mathrm{Cu}(\mathrm{hfa})_{2}\left(0.2 \mathrm{mbar}\right.$ [25]) and between $-25^{\circ} \mathrm{C}$ and $+11^{\circ} \mathrm{C}$ for $\mathrm{H}_{2} \mathrm{O}$ (between 0.59 and 13 mbar [26]). When thermal stability was reached, the hydrogen flow was split in two parts which were sent through the $\mathrm{Cu}(\mathrm{hfa})_{2}$ and $\mathrm{H}_{2} \mathrm{O}$ containers. These two flows were combined prior to entering the reactor. The pressure in the region where the gas mixing occurs was regulated by an electrovalve placed before the reactor entrance, and was independent of the pressure inside the reactor; the latter was set by a manual valve limiting the pumping speed. After the deposition, the reactor and sample were cooled to room temperature under pure hydrogen flow.

The samples were observed by optical microscopy, and the thickness of the deposits was measured with a stylus profilometer (Tencor). The resistivity of the copper films was determined using a four-point method, and divided by that of bulk copper [26] to provide a relative resistivity (or resistivity ratio).

\section{RESULTS AND DISCUSSION}

The thickness of copper deposited in a 10 minute CVD step is reported in Fig. 2 as a function of the ratio of the partial pressures (i.e., of the flows in mol per unit time) of $\mathrm{H}_{2} \mathrm{O}$ and $\mathrm{Cu}(\mathrm{hfa})_{2}$ in the reagent gas mixture. This ratio is the quantity which was changed experimentally, by varying the hydrogen flow and/or the temperature of the water container, resulting in gas mixtures with different fractions of water. It was determined using a transpiration technique [27] to measure the mass flows of $\mathrm{Cu}(\mathrm{hfa})_{2}$ and $\mathrm{H}_{2} \mathrm{O}$. In our conditions the mass of $\mathrm{Cu}(\mathrm{hfa})_{2}$ transported depends linearly on the total flow rate, which means that the partial pressure of $\mathrm{Cu}(\mathrm{hfa})_{2}$ in the flow is constant. For $\mathrm{H}_{2} \mathrm{O}$ the mass transported in the hydrogen flow at different temperatures of the container depends linearly on the equilibrium vapor pressure of water at that temperature. 


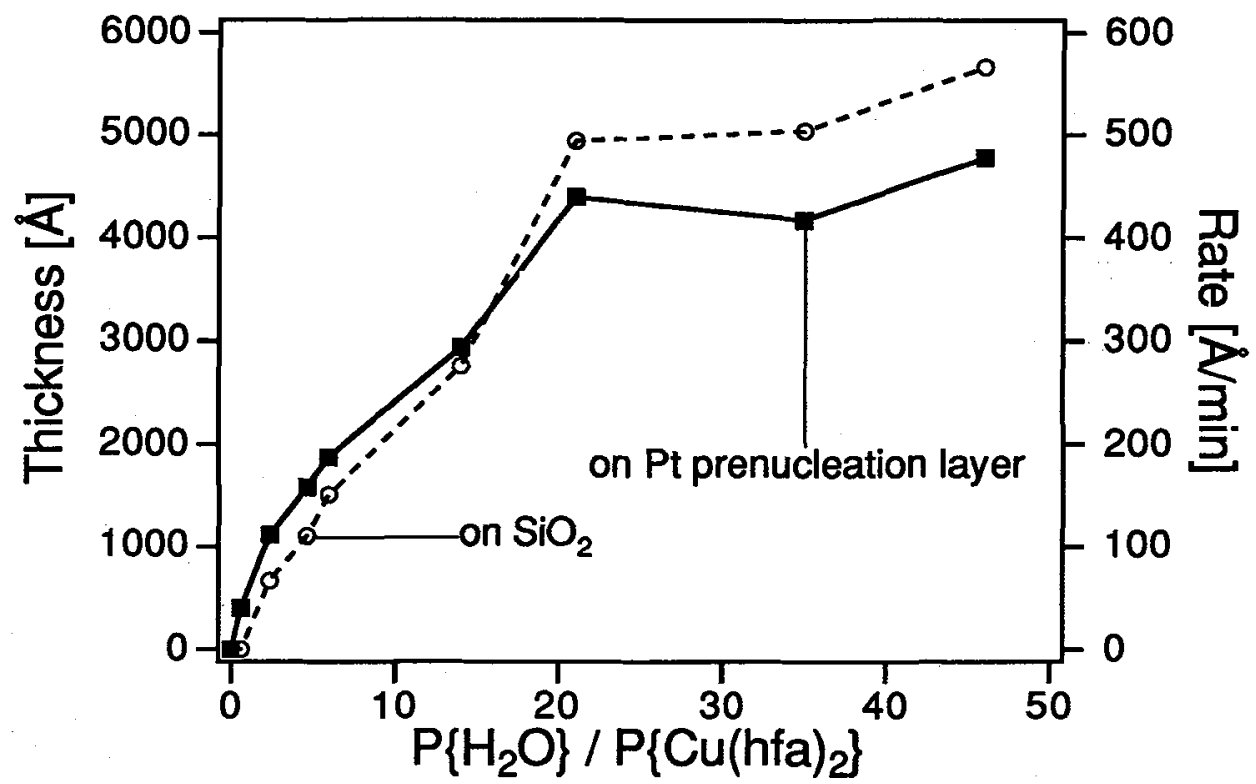

Fig. 2 The thickness of the copper deposit on the $\mathrm{Pt}$ prenucleation layer and on the $\mathrm{SiO}_{2}$ substrate as a function of the ratio of the partial pressures of $\mathrm{H}_{2} \mathrm{O}$ and $\mathrm{Cu}(\mathrm{hfa})_{2}$ in the gas mixture. The substrate temperature was $400^{\circ} \mathrm{C}$, the pressure inside the reactor $1 \mathrm{mbar}$, the total flow of $\mathrm{H}_{2} 50 \mathrm{sccm}$, the vapor pressure of $\mathrm{Cu}(\mathrm{hfa})_{2} 0.2 \mathrm{mbar}$ and the deposition time $10 \mathrm{~min}$. The temperature of the water and the ratio of the flows through the $\mathrm{H}_{2} \mathrm{O}$ and $\mathrm{Cu}(\mathrm{hfa})_{2}$ containers were varied. The deposition rates are calculated from the thickness and the deposition time.

As shown in Fig. 2, the increase of the amount of water relative to the $\mathrm{Cu}(\mathrm{hfa})_{2}$ leads to a marked increase of the thickness of copper deposited in a 10 minute CVD process, and a saturation in the thickness attained is observed at high water content. Two series of measurements appear in Fig. 2: the thickness of the deposit obtained on top of the platinum prenucleation layer as well as that found on the non-prenucleated $\mathrm{SiO}_{2}$ substrates. At high $\mathrm{H}_{2} \mathrm{O}: \mathrm{Cu}(\mathrm{hfa})_{2}$ ratios, the thickness of the deposit is about the same on the whole sample surface, whereas at low water pressure the copper growth takes place exclusively on the prenucleated areas. Fig. 3 shows two typical examples of deposits obtained in these two extreme situations. In both cases, the square pads were covered by $2.5 \AA$ platinum, whereas the rest of the surface was masked by the grid wires during the evaporation of the prenucleation layer; the samples were then exposed to a 10 minute CVD process. A $400 \AA$. copper deposit on top of the prenucleation layer is obtained for the low water content case, with no copper on the areas that have not been seeded. A roughly $0.5 \mu \mathrm{m}$ copper film on the 


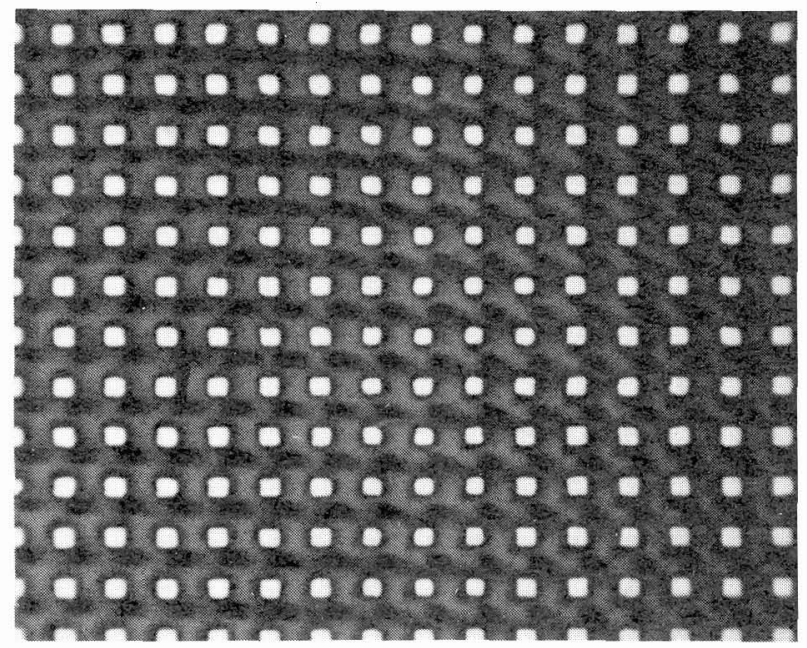

a) $\mathrm{P}\left\{\mathrm{H}_{2} \mathrm{O}\right\} / \mathrm{P}\left\{\mathrm{Cu}(\mathrm{hfa})_{2}\right\}=0.59$

$120 \mu \mathrm{m}$

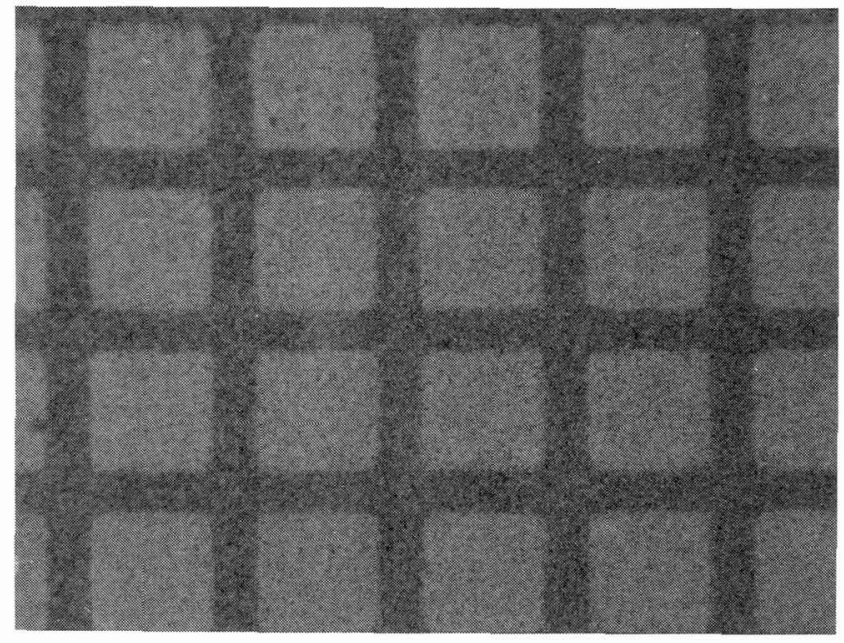

b) $\mathrm{P}\left\{\mathrm{H}_{2} \mathrm{O}\right\} / \mathrm{P}\left\{\mathrm{Cu}(\mathrm{hfa})_{2}\right\}=35$

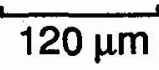

Fig. 3 Optical photograph of copper deposits obtained at two different partial pressures of water. The square pads were covered by $2.5 \AA$ platinum prenucleation films. The conditions for the CVD step are the same as in Fig. 2. 
whole sample surface is obtained for the high water content experiment. In the latter case, the deposit (Fig. 3 b) still shows a contrast between the areas with and without platinum prenucleation. This morphology contrast at high $\mathrm{H}_{2} \mathrm{O}$ partial pressure and the possibility of selective deposition at low water pressure both indicate that the catalytic activity of the platinum prenucleation layer is transferred in some way to the growing copper deposit.

It must be emphasized that the apparent loss of selectivity in the deposition when increasing the water content is valid for our 10 minute CVD time. However, we could observe visually that at high water vapour pressure the deposition always begins on the prenucleated areas, and then (after typically one minute) also starts on the non-prenucleated areas. Thus, in our conditions, it may still be possible to obtain a selective growth at high water content if short exposure times are used.

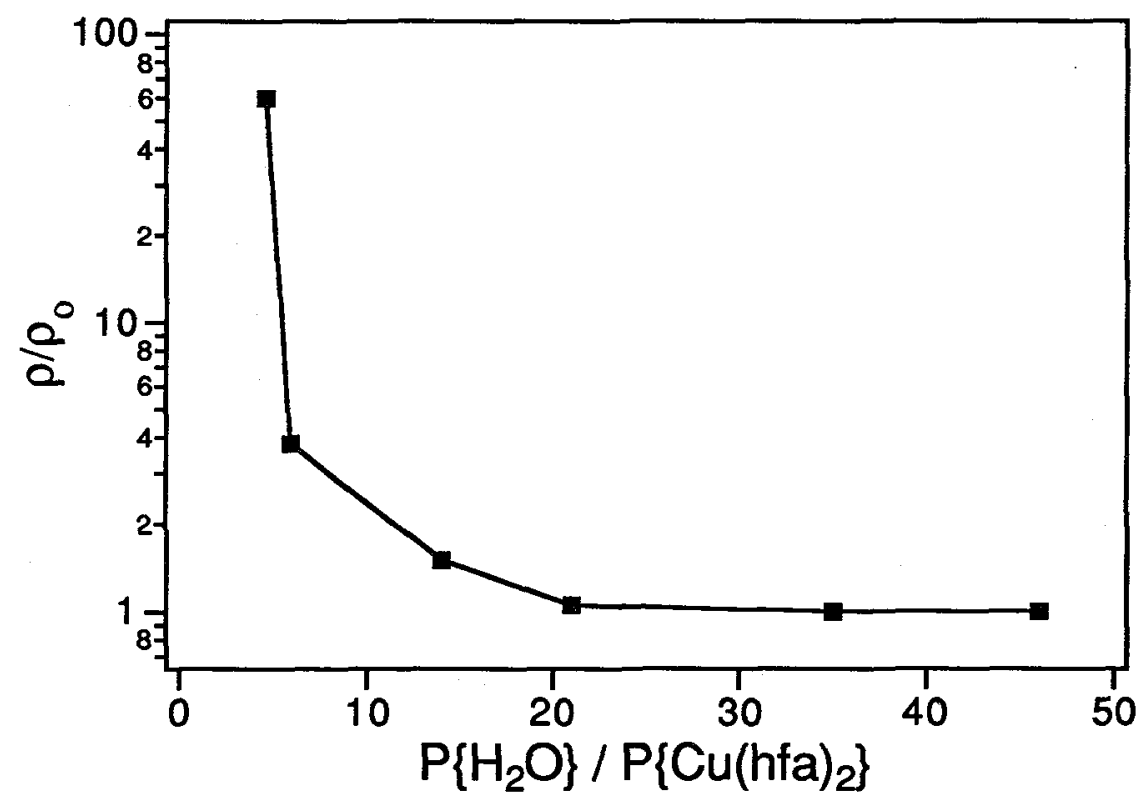

Fig. 4 Relative resistivity of the copper deposit as a function of the ratio of the partial pressures of $\mathrm{H}_{2} \mathrm{O}$ and $\mathrm{Cu}(\mathrm{hfa})_{2}$ in the gas mixture. The conditions are the same as in Fig. 2 .

If we assume to a first approximation that copper deposition proceeds at a constant rate without an induction period, which appears to be the case for the copper growth on top of the prenucleation layer, it is possible to convert the thickness data of Fig. 2 into growth rates; the latter appear on the right hand axis in Fig. 2. These rates can be compared with an upper limit of the deposition rate calculated using a model based on a transport mechanism in 
a stagnation flow reactor. The model simply assumes that each precursor molecule hitting the sample has a unit probability to decompose instantaneously to metal sticking to the surface and volatile products leaving the surface, so that the growth rate is only limited by the transport of precursor molecules to the sample and not by the decomposition kinetics. We obtain an upper limit of the deposition rate equal to $670 \AA / \mathrm{min}$ in our conditions. This value is slightly above the rate obtained at high water vapour pressure, which indicates that transport may start to limit the deposition rate in these conditions.

The resistivity, relative to that of bulk copper, of the deposits obtained in these experiments is shown in Fig. 4: at high partial pressure of water vapour, the measured resistivity is less than 1.1 times that of bulk copper. This is an indication of the good morphology and high purity of these copper deposits. At lower partial pressure of water, the resistivity is higher, and this is in agreement with our previous results [23] obtained using $\mathrm{Cu}(\mathrm{hfa})_{2}$ where resistivity ratios of the order of 3 were observed.

Our observations show that the presence of water has a strong influence on the CVD of copper using $\mathrm{Cu}(\mathrm{hfa})_{2}$ as precursor: the deposition rate is higher and better quality copper is obtained. It is not clear at present whether this effect is due to the interaction of water with the substrate, the prenucleation layer, the precursor or the copper deposit itself. An enhanced nucleation rate on the surface, a different decomposition mechanism due to the possibility of formation of a mono- or di-hydrate in the gas phase or on the surface, and/or a faster removal of the by-products could all contribute to the observed effects. Experiments are in progress to bring out the dominant factors, using different substrates and prenucleation layers, and other compounds instead of water.

\section{ACKNOWLEDGEMENTS}

We thank the Swiss National Science Foundation (PN 13 and PN 24) and the CERS for supporting this project.

\section{REFERENCES}

[1] COle H.S., LiU Y.S., ROSE J.W. and Guida R., Appl. Phys. Lett. 53 (1988) 2111.

[2] HigaSHI G.S., Appl. Surf. Sci. 43 (1989) 6.

[3] Blonder G.E., Higashi G.S. and Fleming C.G., Appl. Phys. Lett. 50 (1987) 766.

[4] KUNZ R.R. AND MAYER T.M., Appl. Phys. Lett. 50 (1987) 962.

[5] ESROM H., WAHL G. and STUKe M., Mat. Res. Soc. Symp. Proc. 131 (1989) 581.

[6] MÜller H.G., Appl. Phys. Lett. 56 (1990) 904.

[7] Pai P.-L., TING C.H., Chiang C., Wei C.-S. and Fraser D.B., Mat. Res. Soc. Symp. Proc. VLSI V (1990) 359.

[8] LECOHIER B. and VAN DEN BERGH H., Appl. Surf. Sci. 43 (1989) 61. 
[9] LIFSHITZ N., WILlIAMS D.S., CAPIO C.D. and BROWN J.M., J. Electrochem. Soc. 134 (1987) 2061.

[10] WILsON R.H. and WILliams A.G., Appl. Phys. Lett. 50 (1987) 965.

[11] ARITA Y., Mat. Res. Soc. Symp. Proc. VLSI V (1990) 335.

[12] HazUKI Y., YaNo H., HoROKIa K., HaYasaka N. and OKaNo H., Mat. Res. Soc. Symp. Proc. VLSI V (1990) 351.

[13] KElber J.A., BlewER R.S., LUJAN R.D. and GuTIERREZ G., Mat. Res. Soc. Symp. Proc. VLSI V (1990) 345.

[14] GuPTA A. and ChEN C.J., Appl. Phys. Lett. 56 (1990) 2516.

[15] JACKMAN R.B. and FOORD J.S., Appl. Phys. Lett. 49 (1986) 196.

[16] MATSUI S. and MORI K., J. Vac. Sci. Technol. B 4 (1986) 299.

[17] KOOPS H.W.P., WEIEL R., KERN D.P. and BAUM T.H., J. Vac. Sci. Technol. B 6 (1988) 477.

[18] Craighead H.G. and SChiavone L.M., Appl. Phys. Lett. 48 (1986) 1748.

[19] BLAUNER P.G., RO J.S., BUTT Y. and MELNGAILIS J., J. Vac. Sci. Technol. B 7 (1989) 609.

[20] HarriotT L.R., CUMmingS K.D., Gross M.E. and BROWN W.L., Appl. Phys. Lett. 49 (1986) 1661.

[21] RO J.S., DUBNER A.D., THOMPSON C.V. and MELNGAILIS J., J. Vac. Sci. Technol. B 6 (1988) 1043.

[22] Shedd G.M., LeZEC H., DubneR A.D. and MElNGallis J., Appl. Phys. Lett. 49 (1986) 1584.

[23] LECOHIER B., PHIIPPOZ J.-M. and VAN DEN BERGH H., J. Vac. Sci. Technol. B, submitted.

[24] HEAVENS O.S., J. Sci. Instrum. 36 (1959) 95.

[25] WOLF W.R., SIEVERS R.E. and BROWN G.H., Inorg. Chem. 11 (1972) 1995.

[26] WEAST R.C., "CRC Handbook of Chemistry and Physics" $58^{\text {th }}$ ed. (CRC Press Inc: Cleveland, 1977).

[27] REISMAN A., BERKENBILT M. and ALYANAKYAN S.A., J. Electrochem. Soc. 112 (1965) 241; TEMPLE D. and REISMAN A., J. Electrochem. Soc. 136 (1989) 3525. 